\title{
The Determinants of the Rural Disabled Person's Behavior of Receiving Rehabilitation
}

\author{
Xia Luo*, Xiang Wu, Shuangzhou Liang, Pu Bu \\ School of Management, Anhui University, Hefei, China \\ Email: ${ }^{*}$ luoxiay@163.com
}

Received 11 August 2015; accepted 19 September 2015; published 22 September 2015

Copyright (C) 2015 by authors and Scientific Research Publishing Inc.

This work is licensed under the Creative Commons Attribution International License (CC BY). http://creativecommons.org/licenses/by/4.0/

(c) (i) Open Access

\section{Abstract}

People with disabilities in rural areas form a special social group in straitened circumstances. They are suffering from impairments, activity limitations, and participation restrictions, which make their situation more severe. As a basic civil right for the disabled, rehabilitation service is an important approach to the recovery of their health and a great help for them to step into society confidently. The objective of this study is to survey the rural disabled people with regard to the important factors that affect their behavior of receiving rehabilitation. 373 questionnaires were sent out and 360 questionnaires were returned (96.5\% return rate). The regression analysis was used to analyze the determinants of receiving rehabilitation. The Binary Logistic Regression Model showed that individual factors, family factors, disability characteristic factors and cognitive factors had significant influence on the choice of rehabilitation for the rural disabled. Among these factors, the variables like level of education $(P<0.01)$, life not fully providing for oneself $(P<0.05)$, level of understanding of rehabilitation service $(\mathrm{P}<0.01)$, degree of satisfaction about work on the disabled $(P<0.05)$, cognition of rehabilitation demand $(P<0.01)$, and net income of households $(P$ $<0.1$ ) had significantly positive correlation with the choice. While other variables like the number of the disabled in a family $(\mathrm{P}<0.01)$ and congenital disability $(\mathrm{P}<0.01)$ had significantly negative correlation with the choice. Rehabilitation for the people with disabilities could be improved by enhancing the education of the disabled in rural areas, paying more attention to impoverished disabled family, perfecting and enforcing implement of the rehabilitation policies, raising the work efficiency of the relative agents, and advocating the rehabilitation policies more sufficiently.

\section{Keywords}

The People with Disabilities, Behavior of Receiving Rehabilitation, Determinants

${ }^{*}$ Corresponding author. 


\section{Introduction}

A disabled person refers to one who suffers from abnormalities of loss of a certain organ or function, psychologically or physiologically, or in anatomical structure and has lost whole or part of the ability to perform an activity in the way considered normal. The term "the people with disabilities" refers to those with visual, hearing, speech or physical disabilities, mental retardation, mental disorder, multiple disabilities and/or other disabilities [1]. Up to now, there are 650 million disabled individuals all over the world, accounting for $10 \%$ of the world's total population [2]. The total number of the disabled in China was 82.96 million. Among them, the majority (62.25 million, 75\% of all the disabled population) were in the rural areas [3]. The disabled form a special social group in straitened circumstances [4]. They are suffering from intense physical or mental pain; and what makes their situation more severe, to some extent, is the social exclusion [5]. The aim of all rehabilitation is to help a person to attain his optimal capability [6]. As an economically viable concept of most countries [7], rehabilitation service is an important approach to the recovery of their health and a great help for them to step into society confidently [8]-[10].

The connotation of the rehabilitation for the disabled has been beyond the limitation of physical rehabilitation, which also involves education, vocation, psychology and social support [11]. The quality of life of the most severely disabled can be improved with education [6]. And education was considered as the key to rehabilitation [12]. Vocational rehabilitation assists individuals with injuries or disabilities to identify career goals, trains them in required skills and matches individuals to best-suited career options [13] [14]. It is a key process in work disability and a fundamental human right of people with disabilities [15]-[17]. Generally, rehabilitation for the disabled consists of medical rehabilitation [18], psychological rehabilitation [19]-[21], vocational rehabilitation and social rehabilitation [22]. Since the end of the 1970s, the model of rehabilitation has gradually changed from biomedical model to bio-psycho-social medical model [23] [24]. However, physical rehabilitation is undoubtedly the most basic model. Due to the influences of many different factors (history, for example), rehabilitation service is still in its infancy in the vast rural areas of China; therefore it is especially important and pressing. Under several major projects carried out in 2011, 6.31 million disabled persons got recovery in varying degrees. According to Monitoring Report on Conditions and Well-off Process of Disabled Persons in China in 2012, the proportion of the disabled persons who had received rehabilitation services was $55.2 \%$, increased by $7.8 \%$ compared with the previous year (47.4\%), of which $63.0 \%$ were from urban areas and only $52.6 \%$ from rural areas.

In recent years, researches on rehabilitation of the disabled are rising, and some scholars focused their studies on evaluating the rehabilitation outcome. I Väänänen-Tomppo held that general working capacity, mental wellbeing and occurrence and the sense of coherence can be used to evaluate the outcome [25]. Rubin SE pointed out that the aim of rehabilitation is to integrate the disabled into society, so changes in life skills and quality of life are two aspects to evaluate rehabilitation outcome [26]. Over the last decade, there has been a dramatic increase in research on technologies for enhancing movement training and exercise for people with a disability [27]. A growing number of scholars believed that technology is playing a more and more important role in rehabilitation and they tried to develop the technology for rehabilitation. Mike Topping gave us an overview of the development of a rehabilitation robot to assist the severely disabled [28]. Hyung Joon Sim introduced a 6-degree-of-freedom robot for physical exercise and rehabilitation for stroke patients or patients [29].

However, researches about determinants of the disabled person's behavior of receiving rehabilitation are quite few. The results of research are mainly indicated on two aspects as follows:

1) Researches about determinants of the urban disabled person's behavior of receiving rehabilitation. Some scholars reported that the disabled person with low age, high level education and income had high demand of rehabilitation [30]. Through epidemiology investigating the rehabilitation service at Xuanwu district in Beijing, Dai Hong, Xue Hui found that the fee of rehabilitation service, the understanding degree of rehabilitation and the effect of the rehabilitation were main influencing factors of receiving rehabilitation [31]. The study of Liu Baofen, et al. pointed out that influencing factors of receiving rehabilitation were the level of education, length of disability, level of understanding of rehabilitation service, attitude of changing current disability status, convenience extent of rehabilitation exercise and reasonable level of rehabilitation fee [32].

2) Researches about the disabled with different types of disabilities. Some scholars analyze the social and family factors influencing rehabilitation of mental retarded children. Gu Changfen, Li Yong conducted a study about children diagnosed as mental retardation in 2004 in Beijing which confirmed degree of disability; receiving education, and attitude of community were main influencing factors [33]. The researcher, Liu Chuang and 
Liu Min reported that age, household nature, income of households and the social assistances were the influencing factors of medical rehabilitation among disabled children [34]. Some scholars focused on the hemiplegic patients about influencing factors of rehabilitation [35]. Che Xiaowen, Ren Nengjun studied the current needs of rehabilitation and influencing factors among rural elderly people with disability and it is a rare achievement on rural disabled. The study showed that gender and age were the influencing factors of needs of rehabilitation; the level of disability influenced demands for the aid devices; disability extent influenced demands for the guidance of rehabilitation training; and level of education and cause of disability were main influencing factors of demands for rehabilitation knowledge [36].

Through detailed review on related literatures, we found that the influencing factors were nothing more than individual factors, family factors, cognition of rehabilitation factors and policies, which will provide beneficial reference for this study. However, the researches of determinants of the disabled person receiving rehabilitation need further investigation. First, most of the achievements focused on rehabilitation willingness or rehabilitation effects but were lack of determinants of behavior of receiving rehabilitation. Second, the existing researches were more concerned with the urban disabled and the rural disabled were ignored. Third, the current researchers studied with small-scale sample data. In this situation, based on the data collected from five counties in Anhui province, quantitative method was used to analyze determinants of rural disabled person's behavior of receiving rehabilitation.

\section{Methods}

\subsection{Data Collection}

The study was based on the data collected from a special subject investigation entitled "Social Security for the Rural Disabled in Anhui Province" that is carried out by the author from July to August in 2012 and rehabilitation services of the disabled is one of important parts. According to the information provided by the Integrated Service Management System of Anhui Disabled Persons' Federation, stratified sampling was used and 5 counties were selected (Feixi, Jieshou, Xiuning, Jingde and Wuwei county) and it covers 31 administrative villages, 5 gerocomiums of 20 villages and towns. Table 1 presents the distribution of samples. A total of 373 questionnaires were sent out and 360 questionnaires were returned, for an effective response rate of $96.5 \%$.

The questionnaire is composed of four parts, including more than 70 variables, which are about the basic information, status qua of the disabilities, social welfare and social security information. The reliable test of the subscale of Cognitive of rehabilitation we used in the statistical model is above 0.8.

Among the survey population, the proportion of the disabled persons who had received rehabilitation was $31.7 \%$; $59.2 \%$ was male and $40.8 \%$ was female; the oldest was 99 years old, and the youngest 16 years old, with a mean age of 54.71 years, of which the age over 60 years is $42.7 \%$, the age between 16 and 59 years is $57.3 \%$; Survey participants had low levels of education, with $1.9 \%$ having a junior college or higher, $5.3 \%$ high school or technical secondary school, 20.8\% high school, 20.8\% junior school, $24.4 \%$ elementary school, and $47.5 \%$ illiterate or knowing little.

\subsection{Setting and Sampling}

Dependent variable: the disabled person's behavior of receiving rehabilitation or not. This study attempts to focus on the determinants of the rural disabled person's behavior of rehabilitation, so the disabled person's behavior of accepting rehabilitation was taken as dependent variable and responses were "accept" and "do not accept".

Table 1. Sample distribution.

\begin{tabular}{ccccc}
\hline & Frequency & Percent & Valid Percent & Cumulative Percent \\
\hline Xiuning & 59 & 16.4 & 16.4 & 16.4 \\
Feixi & 62 & 17.2 & 17.2 & 33.6 \\
Jieshou & 76 & 21.1 & 21.1 & 54.7 \\
Wuwei & 48 & 13.3 & 13.3 & 68.1 \\
Jingde & 115 & 31.9 & 31.9 & 100.0 \\
Total & 360 & 100.0 & 100.0 & \\
\hline
\end{tabular}


Independent variable mainly included the following: individual factors, family factors, disability characteristic factors and cognition of rehabilitation factors. The individual factors were age, gender, level of education, marital status. Family factors consisted of net income of households of the previous year, social security income and the number of the disabled of family. Disability characteristic factors were measured by two variables: self-care ability and congenital disability or not. Cognitive of rehabilitation factors were mainly cognition of rehabilitation demand, level of understanding of rehabilitation service, degree of satisfaction about work on the disabled and attention-degree of government and society. The variables are given in Table 2. Means and standard deviations for each of the explanatory variables are summarized in Table 2.

\subsection{Statistical Model}

In order to analyze determinants of the rural disabled people's behavior of rehabilitation, the regression analysis was used [37]. Suppose that a rural disabled person had the following characteristics: individual, family economic conditions, disability characteristic and cognitive of rehabilitation. Therefore, the probability of the disabled person's behavior of receiving rehabilitation was designated $P$ and not receiving $1-P$. Using a logistic or logit transformations links the dependent variable to the set of explanatory variable. The logit link has the form:

$$
\operatorname{Logit}(P)=\alpha+\beta_{1} x_{1}+\cdots+\beta_{m} x_{m}
$$

In terms of the probability, the model can be written as:

$$
P=\exp \left(\alpha+\beta_{1} x_{1}+\cdots+\beta_{m} x_{m}\right) /\left[1+\exp \left(\alpha+\beta_{1} x_{1}+\cdots+\beta_{m} x_{m}\right)\right]
$$

\begin{tabular}{|c|c|c|c|}
\hline Variable & Explanation & Mean & Standard Deviation \\
\hline \multicolumn{4}{|l|}{ Dependent variable } \\
\hline The behavior of receiving rehabilitation & $1=$ receive, $0=$ not receive & 0.32 & 0.466 \\
\hline \multicolumn{4}{|l|}{ Independent variable } \\
\hline \multicolumn{4}{|l|}{ Individual factors } \\
\hline Gender $\left(x_{1}\right)$ & $1=$ male, 2 = female & 1.41 & 0.492 \\
\hline Age $\left(x_{2}\right)$ & Minimum 16, maximum 99 & 54.71 & 17.572 \\
\hline Marital status $\left(x_{3}\right)$ & $1=$ married, 2 = unmarried & 1.76 & 0.426 \\
\hline Level of education $\left(x_{4}\right)$ & $\begin{array}{l}1=\text { illiterate }, 2=\text { elementary school, } \\
3=\text { junior school or higher }\end{array}$ & 1.81 & 0.848 \\
\hline \multicolumn{4}{|l|}{ Family factors } \\
\hline Net income of households of the previous year $\left(x_{5}\right)$ & $\begin{array}{l}1=\text { below } 1000,2=1001-3000,3=3001-5000 \\
4=5001-10,000,5=10,001-20,000 \\
6=20,001-50,000,7=\text { above } 50,000\end{array}$ & 2.44 & 1.547 \\
\hline Family income mainly from social security income $\left(x_{6}\right)$ & $1=y e s, 2=$ no & 1.78 & 0.414 \\
\hline The number of the disabled of family $\left(x_{7}\right)$ & & 1.317 & 0.5446 \\
\hline \multicolumn{4}{|l|}{ Disability characteristic factors } \\
\hline Self-care ability $\left(x_{8}\right)$ & $\begin{array}{l}1=\text { totally not taking care of themself } \\
2=\text { partly taking care of themself } \\
3=\text { totally taking care of themself }\end{array}$ & 2.31 & 0.706 \\
\hline Congenital disability or not $\left(x_{9}\right)$ & $1=y e s, 2=$ no & 1.72 & 0.450 \\
\hline \multicolumn{4}{|l|}{ Cognitive of rehabilitation factors } \\
\hline Cognition of rehabilitation demand $\left(x_{10}\right)$ & $1=$ demand, 2 = not demand & 1.55 & 0.498 \\
\hline Level of understanding of rehabilitation service $\left(x_{11}\right)$ & $\begin{array}{l}1=\text { very dissatisfied, } 2=\text { not very satisfied } \\
3=\text { neutral, } 4=\text { quite satisfied, } 5=\text { very satisfied }\end{array}$ & 1.95 & 1.010 \\
\hline Degree of satisfaction about work on the disabled $\left(x_{12}\right)$ & $\begin{array}{l}1=\text { very dissatisfied, } 2=\text { not very satisfied, } 3=\text { neutral, } \\
4=\text { quite satisfied, } 5=\text { very satisfied }\end{array}$ & 3.052 & 0.9775 \\
\hline Attention-degree of government and society $\left(x_{13}\right)$ & $\begin{array}{l}1=\text { very dissatisfied, } 2=\text { not very satisfied, } \\
3=\text { neutral, } 4=\text { quite satisfied, } 5=\text { very satisfied }\end{array}$ & 3.220 & 0.9892 \\
\hline
\end{tabular}

Table 2. Variable definitions, means, and standard deviations. 


\subsection{Statistical Analysis}

In the Binary Logistic Regression Model, individual, family, disability characteristic and cognitive of rehabilitation variables were sent into the model. As shown in Table 3: each model had statistical significance and with the increase of variables, the predictive accuracy of the model increased. The accuracy rate of Model-4 was $88 \%$. By comparison, cognitive of rehabilitation had the greatest effect on predictive accuracy of the model and individual factors the smallest. The results showed that variables like level of education, the number of the disabled of family, congenital disability, cognition of rehabilitation demand, level of understanding of rehabilitation service, degree of satisfaction about work on the disabled had significantly correlation with the choice of receiving rehabilitation.

\section{Results and Discussions}

\subsection{Influence of Individual Factors}

Level of education $(\mathrm{P}<0.01)$ had significantly positive correlation with the choice. In the model-1, predictive accuracy of the model increased from $65.8 \%$ to $68.8 \%$ with only $0.3 \%$ rising. This demonstrated that individual factors had little influence on receiving rehabilitation. Only level of education passed significance test and such

Table 3. Regression analysis for determinants of the rural disabled person's behavior of receiving rehabilitation.

\begin{tabular}{|c|c|c|c|c|c|}
\hline & Variable & Model-1 & Model-2 & Model-3 & Model-4 \\
\hline \multirow{2}{*}{\multicolumn{2}{|c|}{ Constant }} & B (S.E) & B (S.E) & B (S.E) & B (S.E) \\
\hline & & $-0.727(0.529)$ & $0.016(0.627)$ & $-0.780(0.693)$ & $-8.407(1.498)$ \\
\hline \multirow{6}{*}{ Individual factors } & Gender(reference group: female) Male & $0.079(0.249)$ & $0.037(0.255)$ & $0.017(0.266)$ & $-0.411(0.395)$ \\
\hline & Age & $0.007(0.009)$ & $0.004(0.009)$ & $-0.004(0.010)$ & $0.024(0.015)$ \\
\hline & $\begin{array}{l}\text { Marital status(reference group: married) } \\
\text { Unmarried }\end{array}$ & $0.494(0.351)$ & $0.609(0.372)$ & $0.080(0.402)$ & $0.333(0.615)$ \\
\hline & Level of education(junior school or higher) & & & & \\
\hline & Illiterate or knowing little & $-0.988^{* * *}(0.302)$ & $-0.788^{* *}(0.312)$ & $-0.645^{*}(0.335)$ & $-0.863^{*}(0.510)$ \\
\hline & Elementary school & $-1.086^{* * *}(0.333)$ & $-0.941^{* * *}(0.345)$ & $-1.000^{* * *}(0.360)$ & $-1.829^{* * *}(0.583)$ \\
\hline \multirow{3}{*}{ Family variables } & Net income of households of the previous year & & $0.161^{*}(0.087)$ & $0.091(0.091)$ & $-0.489^{* * *}(0.154)$ \\
\hline & $\begin{array}{l}\text { Family income mainly from social security } \\
\text { income (reference group: no) Yes }\end{array}$ & & $0.427(0.329)$ & $0.359(0.352)$ & $0.348(0.513)$ \\
\hline & The number of the disabled of family & & $-0.795^{* * *}(0.277)$ & $-0.671^{* *}(0.293)$ & $-0.568(0.446)$ \\
\hline \multirow{5}{*}{$\begin{array}{l}\text { Disability } \\
\text { characteristic }\end{array}$} & Self-care ability (totally taking care of themselves) & & & & \\
\hline & totally not taking care of themselves & & & $-0.496(0.447)$ & $0.130(0.610)$ \\
\hline & Partly taking care of themselves & & & $0.573^{* *}(0.282)$ & $1.219^{* * *}(0.444)$ \\
\hline & Congenital disability or not (No) & & & & \\
\hline & Congenital disability & & & $-1.739^{* * *}(0.411)$ & $-1.371^{* * *}(0.584)$ \\
\hline \multirow{4}{*}{$\begin{array}{l}\text { Cognitive of } \\
\text { rehabilitation }\end{array}$} & $\begin{array}{l}\text { Cognition of rehabilitation demand } \\
\text { (reference group: not demand) Demand }\end{array}$ & & & & $1.592^{* * *}(0.408)$ \\
\hline & Level of understanding of rehabilitation service & & & & $2.587^{* * *}(0.315)$ \\
\hline & $\begin{array}{l}\text { Degree of satisfaction about } \\
\text { work on the disabled }\end{array}$ & & & & $0.642^{* *}(0.314)$ \\
\hline & Attention-degree of government and society & & & & $-0.446(0.304)$ \\
\hline R Square & & 19.993 & 36.919 & 68.356 & 248.462 \\
\hline Df & & 5 & 8 & 11 & 15 \\
\hline \multicolumn{2}{|l|}{-2 Log likelihood } & 427.220 & 410.294 & 378.856 & 198.750 \\
\hline \multicolumn{2}{|l|}{$\begin{array}{l}\text { Nagelkerke } \\
\text { R Square }\end{array}$} & 0.076 & 0.137 & 0.243 & 0.701 \\
\hline
\end{tabular}

${ }^{* * *} \mathrm{P}<0.01,{ }^{* *} \mathrm{P}<0.05,{ }^{*} \mathrm{P}<0.1$. 
variable kept consistent effect in the models. Compared with the disabled with the high school education or above, the proportion of receiving rehabilitation for the disabled who was less dominant, the probability of receiving rehabilitation for the disabled who were illiterate or knew little words was 0.372 times higher than the disabled whose education degree were high school or above. That is to say, the latter was 2.7 times higher than the former. Likewise, the probability of receiving rehabilitation for the disabled whose education degree were high school or above was 3.0 times higher than the disabled whose education degree were elementary school. The reason is that the disabled with high level of education will have deep understanding of the relationship between disability and rehabilitation. Receiving rehabilitation is a method of treating disability to assist the healing process.

Variables like age, gender, marital status had not significant correlation with the rehabilitation for the rural disabled. Age was divided into different age groups and had cross tabulation analysis with receiving rehabilitation, but with no statistical significance; marital status was divided into in marriage and not in marriage, but with no statistical significance; similarly, cross tabulation analysis was used between gender and receiving rehabilitation, but with no statistical significance. This is different from the conclusion of Che Xiaowen, Ren Nengjun [36] and Jia Hongliang, Xie Jingyi, Zhang Gang [38]. They proved the points that gender and age were the influencing factors of needs of rehabilitation [36]. The disabled at low age and the male were less in demand of rehabilitation. That is mainly due to the difference of research object. They put their points on the old disabled, because the old disabled are more at the risk than the young. In general, women live longer than men, and they are eager to get rehabilitation increased with years.

\subsection{Influence of Family Factors}

After analyzing individual factors, the paper set up the family factors model (Model 2), which included net income of households of the previous year, social security income and the number of the disabled of family and the accuracy of the model raised to $69.9 \%$.

The results showed that the number of the disabled of family $(\mathrm{P}<0.01)$ had significantly negative correlation with the choice. It meant the more a family has disabled persons, the less the disabled could receive rehabilitation. Because the disabled receiving rehabilitation will burden the family with investing lots of money, time and energy, and chances of recovery is not of uncertainty.

Net income of households was significant at 0.1 level, and had positive correlation with the rehabilitation. That is to say, with high net income of households, the probability of receiving rehabilitation was higher. The disabled is desirous of recovering from disability, and for a family with high net income of households, it is more willing to put money into rehabilitation.

Social security income had no significant effect on receiving rehabilitation. At present, in many rural regions of China, social security income is very low and the problem of social security for the handicapped is relative critical. Jiang Xiangqun, Hu Liyuan, Li Yuan and Shan Na studied that the proportion of social assistance was still low in regions of China, and lower in many rural regions [39]. The social security income did not significantly affect the disabled persons' willingness of receiving rehabilitation.

\subsection{Influence of Disability Characteristics}

Disability characteristic was introduced and Model 3 was created. The overall accuracy of the model raised to 72.1\%. So there were significant effect on the disabled person's receiving rehabilitation.

Self-care ability $(\mathrm{P}<0.05)$ had significantly negative correlation with receiving rehabilitation. Compared with Group life fully providing for oneself, the probability of receiving rehabilitation for the disabled who can partially provide for oneself was 1.774 times higher than Group life fully providing for oneself. However, there was no significant difference between Group life fully providing for oneself and Group life not providing for oneself. It appeared that the disabled not providing for oneself was more severe and they tended to believe that rehabilitation was really unnecessary, so they gave up treatment. As to the disabled not providing for oneself, they believed it was not a deadly disease, which can be cured when properly treated, so the proportion of receiving rehabilitation was higher.

Congenital disability or not had significantly correlation with receiving rehabilitation. The proportion of receiving rehabilitation for the congenital disabled was 0.176 times higher than the not congenital disabled. It meant that the probability of receiving rehabilitation for the disabled who were not congenital was 5.7 times 
higher than the disabled who were congenital. The reason may be that the disabled who were congenital thought that disability is difficult to recover and there is no need to receive rehabilitation.

\subsection{Influence of Cognition of Rehabilitation}

In model 4, cognition of rehabilitation was introduced. The overall accuracy of the model raised to $88 \%$, which showed that cognition of rehabilitation had the greatest impact on receiving rehabilitation. The findings also echo previous research by Lin Cheng, Luo Hongbo, Chen Xiaohong, Ni Guoxin. They find that the major influence factor for rehabilitation service acceptance was whether or not the disabled have basic knowledge about rehabilitation [40].

Cognition of rehabilitation demand, level of understanding of rehabilitation service and degree of satisfaction had significantly correlation with receiving rehabilitation. By test of significance $(\mathrm{P}<0.05)$, cognition of rehabilitation demand, level of understanding of rehabilitation service and degree of satisfaction passed the test. It presented that the rural disabled with clear cognition of rehabilitation demand had higher proportion of receiving rehabilitation. The higher the extent of satisfaction about work on the disabled was, the higher the proportion of receiving rehabilitation was. The more the disabled understood rehabilitation service, the higher the proportion of receiving rehabilitation was. The proportion of receiving rehabilitation could increase 1.9 times with the extent of satisfaction raised. In the Model 4, attention-degree of government and society were not significant.

\section{Conclusions and Discussions}

As a basic civil right for the disabled, receiving rehabilitation was greatly important in their recovery. Based on the data in Anhui province, binary logistic regression model was used while making analysis in combination with the records of seminars and interviews; summary and discussion were as follows:

Level of education was one of important factors affecting the rural disabled persons receiving rehabilitation. The proportion of receiving rehabilitation for those disabled persons with junior school education or above was 2 - 3 times higher than those with elementary school education or illiterate or knowing little. Results of the study were in line with the works about factors influencing the urban disabled persons receiving rehabilitation by Baofen Wang and Xiuqun Yan [32] and rehabilitation demands of the disabled and influence factors by Lin Cheng, Luo Hongbo, Chen Xiaohong, and Ni Guoxin [40]. Baofen Wang and Xiuqun Yan made the statistical analysis of the data and found that the urban disabled persons with junior school education or above preferred to receive rehabilitation and were 1.119 times higher than those with elementary education or no schooling education.

It was found out that the number of the disabled of a family had negative correlation and financial status had positive correlation with the choice of receiving rehabilitation. During investigation and interview, many interviewees said that they were in a low state of family status and rehabilitation cost a lot to keep up. As to the severe disabled, rehabilitation was a long-term project and the cost put an intolerable burden on them. Results still showed that the average cost of receiving rehabilitation was 722.7 Yuan last month: the average rehabilitation cost of Level 1 disabled was the highest (1225.6 Yuan), and Level 3 disabled was the second (467.9 Yuan). The proportion of free rehabilitation was $5.3 \%$, family undertaking portion $48.7 \%$ and family undertaking nearly all $46 \%$. It appeared that the cost of receiving rehabilitation for the disabled was very high and the family took the greater part of rehabilitation cost. Understandably, the proportion of the disabled receiving rehabilitation in family with good economic conditions was higher than that in family with poor economic conditions.

Statistical analysis indicated that disability characteristic had significant influence on the choice of rehabilitation. Compared with those disabled persons whose lives are providing for themself, the proportion of those disabled persons whose lives are not fully providing for themself is higher in receiving rehabilitation, and the proportion of not congenital disability is higher than congenital disability. This is maybe because it was generally acknowledged that congenital disability was born disabled and pessimistic about chances of recovery. So the proportion of receiving habilitation was low. It showed that cognition of rehabilitation had a great impact on receiving rehabilitation. The proportion of rehabilitation for those disabled persons in need was higher than the opposite. The more understanding of rehabilitation service and work on the disabled, the higher the proportion.

On the basis of the above analysis, strategies were given in the hope of improving rehabilitation for the disabled.

First, raising the level of education and cognition of the disabled. The conclusions of the research showed that 
the level of education and cognition of the rehabilitation played an important role in rehabilitation. The level of education directly determined the level of cognition. For many persons with disabilities, with low level education, it would be impossible for them to truly understand the rehabilitation but a superficial understanding. For example, some of them were under the illusion that home rehabilitation [41] was just insertion or medication at home and that rehabilitation service was ordinary medical treatment. For some persons with disabilities, even if they have the need of rehabilitation, they still have no idea what kind of rehabilitation service they should receive and where they could receive those kinds of rehabilitation service. So, devoting major efforts to developing education among the rural disabled, promoting the level of education and cognition of the disabled are effective methods and will raise proportion of receiving rehabilitation of the disabled.

Second, promoting the employment of the rural disabled. In the research, financial status had positive correlation with the choice of receiving rehabilitation. Employment is an important way to enable the disabled to get income and have a better financial status. Also, it has very important social meanings for the rural disabled. Because of the particular role of the disabled, the government should bear the main responsibility to promote the employment. It is necessary to provide employment assistance and employment promotion for some disabled who cannot find a job [42]. Also, encouraging the disabled to start their own business realizes more employment. For example, the Internet is an effective way to start own business. With a good financial status, the disabled have a better condition to have rehabilitation.

Third, paying special attention to impoverished disabled families and families with more than one disabled person. Usually, the disabled family would be reduced to poverty by lacking of labor, high expenditure on treatment and so on, and family with disabled persons having more than 1 disabled person got worse. In rural areas, among the family with disabled persons, those with 2 disabled persons took up 23.2\%, and those with 3 disabled persons were $4.2 \%$. In other words, one out of four families had 2 or more disabled persons. The majority of the rural disabled lived in impoverished family, and therefore special attention should be paid to impoverished disabled families and families with more than 1 disabled person. Preferential rehabilitation policies should be measured to the disabled persons. For instance, policies like burden-diversification (different government departments and the disabled share certain responsibility), and derating fees were used to solve the problems for the disabled in rehabilitation. In addition, Disabled Persons Federation of a city or county had better actively raised special fund for the rehabilitation service of the disabled; a wide network of "Volunteers Helping the Disabled Rehabilitation" might be built, while rehabilitation service encourages increased participation in making a contribution to the disabled. Rehabilitation institutions should promote programs for the disabled in a humanitarian spirit, cultivate moral integrity and derate rehabilitation fees to those impoverished disabled persons appropriately. Certainly, some support projects could be developed according to local actual conditions. For instance, the writer had investigated that some areas offered "Home-in Rehabilitation Loan" and produced a favorable response from the public.

Fourth, doing more work in publicity of rehabilitation service. Research has shown that the level of understanding of rehabilitation service and the degree of satisfaction about work on the disabled had direct impact on the disabled persons' behavior of receiving rehabilitation. Compared with cities, the work for disabled persons is still in its infancy in the rural areas with few channels of information sources. Besides, whether the staff did well in the work in publicity or not can directly affect the rehabilitation for the disabled as follows: the way which they selected, their passion in the publicity work and their degree of understanding of rehabilitation knowledge. In view of long lasting and complexity of rehabilitation work, doing more work in publicity and improving its publicity way were helpful to make rehabilitation consciousness deeply root among the people so as to approach to the target that "everybody has access to rehabilitation service" actively. Traditional work in publicity put emphasis on publicity materials and made effect accessible to individual households. Different from the traditional way, during publicity of rehabilitation knowledge, conforming local conditions is necessary. For example, when the staff conduct publicity, he or she can provide some examples like real characters and real incidents to help the rural disabled adequately understand how to receive rehabilitation, type and advantages of rehabilitation; also, conferring with the village cadres, recruiting volunteers and making the most of special days carry out activities such as lecture are available to help the disabled understand contents and significances of rehabilitation and improve their consciousness. Eventually, it will raise proportion of receiving rehabilitation of the rural disabled.

In addition, it also states that measures of support and help shall be taken to develop undertakings for the disabled by the government: exploring diversified sources of rehabilitation funding, continuing to strengthen the 
supervision and management and promoting efficiency of fund utilization. The government should plan rehabilitation expenditures of the disabled into government budgets at different levels and establish a stable guarantee mechanism of payment according to the concrete conditions of local economic and social development. Besides, the government can raise funds through a variety of channels used to pay for rehabilitation aid and rehabilitation construction of infrastructural facilities for the disabled. Also, continuing to perfect the construction of rehabilitation system is the basic premise to keep sustainable development of undertakings for the disabled.

The limitation of the study is that the variables considered in the models are not enough and that it is lack of comparison study with the urban areas.

\section{Funding}

The work was financially supported by Humanity and Social Science Foundation of the Ministry of Education, PRC (13YJA840015) and by College Students Research Training Program of Anhui University (2013).

\section{References}

[1] Law of the People's Republic of China on the Protection of Disabled Persons (Revised Edition).

[2] WHO. International Day of Persons with Disabilities. http://www.who.int/mediacentre/events/annual/day_disabilities/en/index.html

[3] Office of the Second China National Sample Survey on Disability (2007) Handbook on the Main Data of the Second China National Sample Survey on Disability. Huaxia Publishing House, Beijing.

[4] Wiener, R.L. and Willborn, S.L. (2010) Disability and Aging Discrimination: Perspectives in Law and Psychology. Springer-Verlag Inc., New York.

[5] David, B. (1999) Social Exclusion. USA Open University Press, New York.

[6] Sinclair, S. (1981) Rehabilitation Mentally Handicapped in India. The Indian Journal of Pediatrics, 48, 715-720. http://dx.doi.org/10.1007/BF02758535

[7] Mukherjee, A.K. (1981) Rehabilitation of the Physically Handicapped. The Indian Journal of Pediatrics, 48, 709-713. http://dx.doi.org/10.1007/BF02758534

[8] Hornik-Lurie, T., Zilber, N. and Lerner, Y. (2012) Trends in the Use of Rehabilitation Services in the Community by People with Mental Disabilities in Israel; The Factors Involved. Israel Journal of Health Policy Research, 1, 24. http://dx.doi.org/10.1186/2045-4015-1-24

[9] Huang, G., Liu, X., He, J., Klawonn, F. and Yao, G. (2013) Health Information Science. Second International Conference, London, 25-27 March 2013. http://dx.doi.org/10.1007/978-3-642-37899-7

[10] Ushikubo, M. (1998) A Study of Factors Facilitating and Inhibiting the Willingness of the Institutionalized Disabled Elderly for Rehabilitation: A United States-Japanese Comparison. Journal of Cross-Cultural Gerontology, 13, 127157. http://dx.doi.org/10.1023/A:1006503909886

[11] Smith, J.N. (1984) Community Responsibility for the Disabled. Annals of the American Academy of Political and Social Science, 239, 87-92. http://dx.doi.org/10.1177/000271624523900112

[12] Hammell, K.W. (1995) Spinal Cord Injury Rehabilitation. Springer US Press, New York. http://dx.doi.org/10.1007/978-1-4899-4451-1

[13] Wagner, C. (2011) Encyclopedia of Clinical Neuropsychology. Springer Press, New York.

[14] Langman, C. (2011) Introduction to Vocational Rehabilitation: Policies, Practices and Skills. Routledge Press, London.

[15] Escorpizo, R., Finger, M.E., Glassel, A. and Cieza, A. (2011) An International Expert Survey on Functioning in Vocational Rehabilitation Using the International Classification of Functioning, Disability and Health. Journal of Occupational Rehabilitation, 21, 147-155. http://dx.doi.org/10.1007/s10926-010-9276-y

[16] Dutta, A., Gervey, R., Chan, F., Chou, C.-C. and Ditchman, N. (2008) Vocational Rehabilitation Services and Employment Outcomes for People with Disabilities: A United States Study. Journal of Occupational Rehabilitation, 18, 326-334. http://dx.doi.org/10.1007/s10926-008-9154-z

[17] Solberg, A. and Raschmann, J.K. (1980) The Effects of Vocational Services Provided to the Mentally Disabled. Community Mental Health Journal, 16, 112-120. http://dx.doi.org/10.1007/BF00778583

[18] Chino, N. and Melvin, J.L. (1996) Functional Evaluation of Stroke Patients. Springer Press, Tokyo. http://dx.doi.org/10.1007/978-4-431-68461-9

[19] Chan, F., Da Silva Cardoso, E. and Chronister, J.A. (2009) Understanding Psychosocial Adjustment to Chronic Illness and Disability: A Handbook for Evidence-Based Practitioners in Rehabilitation. Springer Publishing, New York. 
[20] Langman, C. (2011) Introduction to Vocational Rehabilitation: Policies, Practices and Skills. Routledge Press, London.

[21] Gittelman, M. (1997) Psychosocial Rehabilitation for the Mentally Disabled: What Have We Learned? Psychiatric Quarterly, 68, 393-406. http://dx.doi.org/10.1023/A:1025451215976

[22] Auerbach, E.D. and Pattison, E.M. (1976) Outcome of Social Rehabilitation: Whom Does It Help? Social Psychiatry, 11, 33-40. http://dx.doi.org/10.1007/BF00578798

[23] Engel, G.L. (1977) The Need for a New Medical Model: A Challenge for Biomedicine. Science, 196, 129-136. http://dx.doi.org/10.1126/science.847460

[24] Engel, G.L. (1980) The Clinical Application of the Biopsychosocial Model. American Journal of Psychiatry, 137, 534-544.

[25] Väänänen-Tomppo, I., Janatuinen, E. and Törnqvist, R. (2001) All Well at Work Evaluation of Workplace-Based Early Rehabilitation in the Finnish State Administration. International Journal of Rehabilitation Research, 24, 171-180. http://dx.doi.org/10.1097/00004356-200109000-00002

[26] Rubin, S.E., Chan, F. and Thomas, D. (2003) Assessing Changes in Life Skills and Quality of Life Resulting from Rehabilitation Services. Journal of Rehabilitation, 69, 4-9.

[27] Reinkensmeyer, D.J. and Boninger, M.L. (2012) Technologies and Combination Therapies for Enhancing Movement Training for People with a Disability. Journal of NeuroEngineering and Rehabilitation, 9, 17. http://dx.doi.org/10.1186/1743-0003-9-17

[28] Topping, M. (2000) An Overview of the Development of Handy 1, a Rehabilitation Robot to Assist the Severely Disabled. Artificial Life and Robotics, 4, 188-192. http://dx.doi.org/10.1007/BF02481173

[29] Sim, H.J., Won, J.Y. and Han, C.S. (2004) A Feasibility Study on a Robotic Exercise System for MDOF Physical Rehabilitation Therapy. KSME International Journal, 18, 1949-1960.

[30] Chen, Q. and Li, J.A. (1993) Investigation and Analysis on the Rehabilitation Demands of People with Disabilities. Chinese Journal of Rehabilitation Medicine, 8, 218-219.

[31] Dai, H., Xue, H., Yin, Z.J. and Xiao, Z.X. (2004) The Need of Rehabilitation Objects at Xuanwu District in Beijing to Community-Based Rehabilitation Services and Analysis to Its Influence Factors. Chinese Journal of Rehabilitation Medicine, 19, 915-918.

[32] Liu, B.F. and Yan, X.Q. (2012) Analysis on the Factors Influencing Rehabilitation Service of the Community Disabled. Nursing Practice and Research, 14, 155-156.

[33] Gu, C.F. and Li, Y. (2009) Logistic Regression Analysis of Rehabilitation Needs of Children with Mental Retardation in Beijing. Chinese Journal of Rehabilitation Theory and Practice, No. 2, 185-187.

[34] Liu, C. and Liu, M. (2011) Study on the Medical Rehabilitation and Related Factors of Disabled Children Aged 0-18 in Guangzhou and Dongying Cities. Chinese Journal of Rehabilitation Medicine, 26, 754-758.

[35] Xu, Y.M., Wang, Y. and Hu, Q.F. (2012) Influencing Factors of Hemiplegic Patients’ Rehabilitation and the Effect of Nursing Intervention. Military Medical Journal of Southeast China, 14, 262-263.

[36] Che, X.W. and Ren, N.J. (2012) Analysis for the Influencing Factors of Rehabilitation Needs for Rural Elderly People with Disabilities. Journal of Nurses Training, 22, 2021-2023.

[37] Sen, A. and Srivastava, M.S. (1990) Regression Analysis: Theory, Methods, and Applications. Springer-Verlag, New York.

[38] Jia, H.L., Xie, J.Y. and Zhang, G. (2009) Multivariate Analysis of Rehabilitation Services Needs of People with Disability at Zhabei District in Shanghai. Chinese Journal of Rehabilitation Theory and Practice, No. 2, 194-196.

[39] Jiang, X.Q., Hu, L.Y., Li, Y. and Shan, N. (2011) Status and Requirement of Social Security for the Handicapped in Rural China. Population Journal, 3, 53-60.

[40] Lin, C., Luo, H.B., Chen, X.H. and Ni, G.X. (2009) Analysis of Rehabilitation Demands of the Disabled in Taijiang District of Fuzhou City and Influence Factors. Journal of Fujian Medical University (Social Science Edition), No. 1, 38-41.

[41] Johnson, M.J., Loureiro, R.C.V. and Harwin, W. (2008) Collaborative Tele-Rehabilitation and Robot-Mediated Therapy for Stroke Rehabilitation at Home or Clinic. Intelligent Service Robotics, 1, 109-121. http://dx.doi.org/10.1007/s11370-007-0010-3

[42] Xu, L. (2010) The Difficulty of the Disabled Employment and the Perfection of Employment Promotion Policy. Journal of Northwest University (Philosophy and Social Sciences Edition), No. 1, 116-120. 